\title{
Acquired pseudo-pseudo Bernard-Soulier syndrome complicating Gaucher's disease
}

\author{
H Kelsey, C Christopoulos, A A Gray, S J Machin
}

\begin{abstract}
Aims-To investigate the abnormality in platelet function in two patients with type I Gaucher's disease causing a chronic bleeding tendency despite normalisation of the platelet count after spleen removal. Methods-Routine laboratory methods were used to assess baseline coagulation. Platelet aggregometry was used to assess platelet responses to a range of agonists, and abnormalities were further assessed in mixing experiments using washed platelets and patients' plasma.

Results-Platelets from both patients with Gaucher's disease failed to agglutinate to ristocetin, despite normal platelet surface glycoprotein (GP) Ib and plasma von Willebrand factor activity. The agglutination of normal washed platelets was abolished by incubation in patient plasma. The inhibitory activity did not lie in the IgG fraction of patient plasma, and was found to be loosely associated with the patient platelet surface.

Conclusions-The inhibition of ristocetin induced platelet agglutination in patients with Gaucher's disease causes a prolonged skin bleeding time. This could be due to the accumulated glucocerebroside in the plasma coating the platelet membrane. It is suggested that the term pseudo-pseudo Bernard-Soulier syndrome would be appropriate, as on initial screening, the abnormality has the features of Bernard-Soulier syndrome, but further investigation shows normal plasma von Willebrand activity and platelet surface GP Ib concentrations. The inhibitory activity is not due to a platelet specific antibody as is the case in pseudo-Bernard Soulier syndrome.
\end{abstract}

(F Clin Pathol 1994;47:162-165)

Department of Haematology, University College, London

H Kelsey

C Christopoulos

S J Machin

Princess Margaret Hospital, Swindon A A Gray

Correspondence to: Dr H C Kelsey,

Department Haematology,

University College Hospital,

Gower Street, London Gower Street,
WC1E 6AU

Accepted for publication 7 September 1993

Gaucher's disease is the most common of the lysosomal storage disorders. It is characterised by deficiency of the lysosomal enzyme glucocerebrosidase, resulting in accumulation of the sphingolipid glucocerebroside in the plasma and cells of the reticuloendothelial system. ${ }^{1}$ It is autosomal recessive and comprises three types, characterised by the age of onset and degree of involvement of the nervous system. Type 1 or chronic non-neuronopathic Gaucher's disease is the most common form, with a particularly high incidence ( 1 in 600 to 1 in 2500) among Ashkenazim (Polish and German Jews). It is characterised by often massive splenomegaly with hypersplenism and pancytopenia.

Pathologically lipid-laden macrophagesthe Gaucher cells - are found in the red pulp of the spleen, liver sinusoids, and the bone marrow. Plasma concentrations of glucocerebroside are raised 2- to 10-fold, and in the spleen grossly raised 10-1000 fold. ${ }^{1}$ Diagnosis has typically been by enzyme assay in peripheral blood leucocytes or tissue fibroblasts. With the advent of molecular methods, diagnosis on the basis of detection of the abnormal or missing gene has become possible. ${ }^{2}$

Until recently management of Gaucher's disease was supportive with the main therapeutic manoeuvre being removal of the spleen for hypersplenism and excessive bleeding. This usually corrects the thrombocytopenia and anaemia, but may worsen the bone disease. More recently treatment with enzyme replacement has become possible with mannose conjugated glucocerebrosidase. ${ }^{3}$ Thrombocytopenia (often less than $50 \times 10^{\%} / 1$ ) predisposes to a bleeding diathesis, which may aggravate the anaemia, due to hypersplenism. The bleeding tendency may be disproportionate to the degree of thrombocytopenia. ${ }^{1}$ Hepatic disease may be associated with abnormalities in clotting factor synthesis, ${ }^{4}$ causing a prolonged prothrombin time. The raised circulating glucocerebroside concentration may interfere with the clotting cascade. ${ }^{5}$ Here we describe an abnormality in platelet function in two adults with type 1 Gaucher's disease in whom a bleeding tendency persisted despite spleen removal, relative normalisation of the platelet count, and normal liver function tests and coagulation screen.

\section{Methods}

CASE REPORTS

A 47 year old woman (Ashkenazim) was diag nosed as having Gaucher's disease when she was 14 years old after dental extraction led to excessive bleeding. The platelet count at this time was $<15 \times 10^{\circ} / 1$. Her spleen was removed because of massive enlargement when she was 24. Easy bruising and bleeding continued despite improvement of the platelet count, and when she was 37 her left hip was replaced. Bleeding was excessive both during and after surgery, requiring red cell transfusion and platelet transfusion for haemostasis. Seven years later her right hip 
was replaced, bleeding at which was successfully prevented by prophylactic platelet transfusions. As a result of red cell and platelet transfusion she formed several red cell and HLA antibodies. After the second hip operation an anaphylactic transfusion reaction occurred despite transfusing compatible blood. Subsequently an additional red cell antibody was found. Since recovery, three units of autologous blood have been placed in long term storage.

A 23 year old caucasian woman was found to have Gaucher's disease as a child. She had epistaxis and severe menorrhagia as a child and in addition to thrombocytopenia a platelet function abnormality was detected but could not be further defined. When she was 15 years old her spleen was removed for hypersplenism. On recovery the bleeding problems persisted, with heavy menorrhagia despite a normal platelet count. She developed extensive bruising at the time of a road traffic accident when, aged 19 years, she sustained a fractured pelvis. She was referred for investigation of a bleeding tendency when surgical correction of the damage sustained was contemplated.

Blood was collected from the two patients on three separate occasions into EDTA for full blood and platelet counts (STK S, Coulter Electronics, Florida, USA) and into $3.13 \%$ trisodium citrate in a ratio of 9 parts blood to 1 part trisodium citrate, for coagulation and platelet function studies. Control plasma and platelets were similarly collected from normal male volunteers. Prothrombin time (PT), thrombin time (TT), and activated partial thromboplastin time (APPT) were performed by routine techniques. ${ }^{6}$ Factor VIIIc was assayed by a one stage automated method, von Willebrand factor antigen (vWF:Ag) by ELISA, and ristocetin cofactor activity (vWF:RiCoF) by platelet agglutination. Von Willebrand multimers were assessed by sodium dodecyl sulphate gel electrophoresis, as described before ${ }^{6}$ and platelet nucleotides (adenosine triphosphate, adenosine diphosphate; total and releasable) using a luciferase firefly luminescence technique. ${ }^{6}$ Platelet glycoproteins (GP) Ib and IIb/IIIa, platelet surface immunoglobulin, and free platelet bindable immunoglobulin were assessed by a fluorescence flow cytometric method. ${ }^{7}$

Bleeding time was assessed with a template method and platelet aggregometry ${ }^{6}$ performed in a four channel aggregometer using the following agonists: ristocetin (Lundbeck, Luton, England) $1.25,1.0,0.7,0.5 \mathrm{mg} / \mathrm{ml} ; \mathrm{ADP}$ (Sigma Chemical Co Ltd, Poole, Dorset) 5.0, $2.5, \quad 1.0,0.5 \mu \mathrm{mol} / 1$; collagen (Hormon Chemie, Munich, Germany) $4.0,1.0 \mu \mathrm{g} / \mathrm{ml}$; and arachidonate (Sigma) $1.0 \mu \mathrm{M}$. Porcine FVIII complex (Porton, Maidenhead, Berkshire) and cryoprecipitate were used in correction studies with ristocetin.

In mixing experiments washed platelets were used (three washes in Tyrodes buffer with 10 $\mathrm{mM}$ EDTA and $10 \mathrm{ng} / \mathrm{ml}$ prostacyclin analogue (ZK36 374 Schering Chemicals) and then resuspended in 1:4 human albumin with
Tyrodes buffer, as described before. ${ }^{6}$ Patient and control platelets were then incubated with patient or control plasma and agglutination to ristocetin tested immediately and after 1 hour of incubation at room temperature. Immunoglobulin $G$ fractions of patient and control sera were isolated by affinity chromatography using a protein $\mathrm{G}$ column, eluted with glycine $\mathrm{HCl}$ buffer ( $\mathrm{pH} 2 \cdot 8$ ), and then dialysed against phosphate buffered saline $(\mathrm{pH} 7 \cdot 2)$ to give a final concentration of 5-10 $\mathrm{mg} / \mathrm{ml}$. IgG fractions were incubated with washed platelets for one hour and cryoprecipitate then added before testing ristocetin induced agglutination.

\section{Results}

Both patients had normal platelet counts and initial clotting screens (table). The bleeding time was $>15$ minutes in both cases. Platelet aggregation responses to adenosine diphosphate, collagen, and arachidonic acid were normal (table). Ristocetin induced agglutination was absent at all concentrations tested. This did not correct with procine F VIII, or cryoprecipitate and ristocetin, and there was no agglutination on the addition of cryoprecipitate alone (representative traces fig 1A). Factor VIIIc and vWF:Ag and vWF:RiCoF activities were normal (table).

Platelet surface glycoproteins $\mathrm{Ib}$ and IIb/IIIa were present in normal amounts on both patients' platelets. Free platelet bindable immunoglobulin was detected in both patient sera, and platelet surface immunoglobulin was raised in the second patient. This immunoglobulin reacted with Bernard-Soulier platelets in both cases (results not shown).

The response of washed normal platelets to ristocetin was abolished after 1 hour of incubation in patient plasma (fig 1B). This inhibitory activity was not present in the IgG fraction of patient sera (fig 2A). The inhibitory activity was loosely associated with patient platelets as washing of patient platelets restored ristocetin responses when they were tested immediately after resuspending in

Results of initial investigations-full blood count, coagulation screen, platelet aggregation and bleeding time-patient and control values

\begin{tabular}{|c|c|c|c|}
\hline Parameter & Case 1 & Case 2 & Normal \\
\hline $\begin{array}{l}\text { Platelets } \times 10^{9} / 1 \\
\text { PT (control) } \\
\text { APTT (control) } \\
\text { TT (control) } \\
\text { F VIIIc } \\
\text { vWF Ag } \\
\text { vWF Ricof } \\
\text { vWF multimers } \\
\text { Platelet nucleotides } \\
\text { GP Ib } \\
\text { GP IIb/IIIa } \\
\text { PSIgG } \\
\text { Platelet aggregation: } \\
\text { Ristocetin } 1.25 \mathrm{mg} / \mathrm{ml} \\
\quad 1.0 \mathrm{mg} / \mathrm{ml} \\
\quad 0.7 \mathrm{mg} / \mathrm{ml} \\
\quad 0.5 \mathrm{mg} / \mathrm{ml} \\
\text { ADP } \\
\text { Collagen } \\
\text { Arachidonate } \\
\text { Bleeding time }\end{array}$ & $\begin{array}{l}179 \\
13 \mathrm{~s}(12) \\
39 \mathrm{~s}(36) \\
10 \mathrm{~s}(13) \\
0 \cdot 95 \\
1 \cdot 35 \\
1 \cdot 75 \\
\text { Normal } \\
\text { Normal } \\
\text { Normal } \\
\text { Normal } \\
\text { Normal } \\
\\
\text { Absent } \\
\text { Absent } \\
\text { Absent } \\
\text { Absent } \\
\text { Normal } \\
\text { Normal } \\
\text { Primary } \\
\text { wave } \\
>15 \mathrm{~m}\end{array}$ & $\begin{array}{l}174 \\
15 \mathrm{~s}(13) \\
39 \mathrm{~s}(43) \\
16 \mathrm{~s}(13) \\
0 \cdot 66 \\
0 \cdot 78 \\
0 \cdot 85 \\
\text { Normal } \\
\text { Normal } \\
\text { Normal } \\
\text { Normal } \\
\text { Normal } \\
\\
\text { Absent } \\
\text { Absent } \\
\text { Absent } \\
\text { Absent } \\
\text { Normal } \\
\text { Normal } \\
\text { Primary } \\
\text { wave } \\
>15 \mathrm{~m}\end{array}$ & $\begin{array}{c}150-450 \\
11-15 \mathrm{~s} \\
30-40 \mathrm{~s} \\
11-15 \mathrm{~s} \\
0 \cdot 5-2 \cdot 0 \\
0 \cdot 5-2 \cdot 0 \\
0 \cdot 5-2 \cdot 0\end{array}$ \\
\hline
\end{tabular}


Figure 1 (A) Patient platelet responses to ristocetin alone $(1.25$ $\mathrm{mg} / \mathrm{ml}$ ), porcine FVIII (2 IUIml), cryoprecipitate and cryoprecipitate with agglutination response of washed control platelets with Gaucher patient plasma for 1 hour. ristocetin. (B) Ristocetin before and after incubating

A

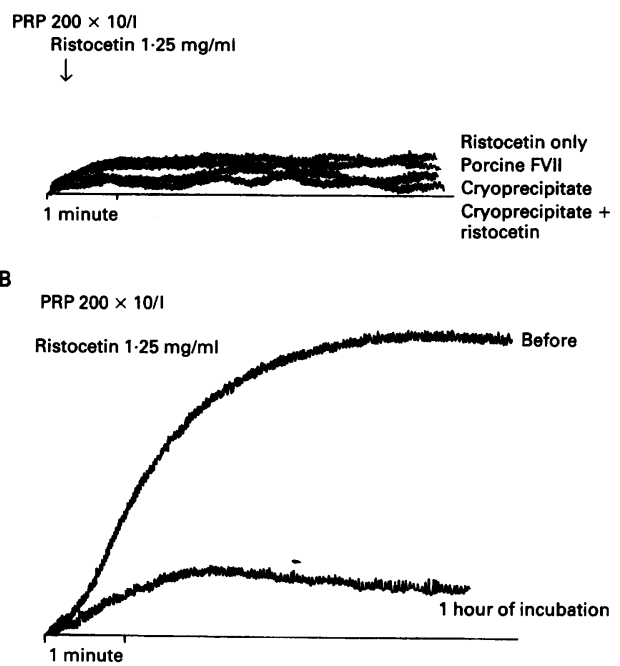

patient plasma. Reincubation in patient plasma for 1 hour resulted in loss of the response compared to patient platelets incubated in normal plasma (fig 2B).

\section{Discussion}

These two patients with well characterised Gaucher's disease had a persistent bleeding tendency despite normalisation of the platelet count after spleen removal. In one case this led to severe bleeding during and after surgery, and in the other to persistent menorrhagia resulting in chronic anaemia. Abnormalities in clotting factors in Gaucher's disease may be caused by impaired synthesis secondary to liver disease. In addition, prolongation of the APTT has been described due to interference by plasma sphingolipid in the phospholipid dependent phases of coagu-

Figure 2 (A) Effect of prior incubation of washed platelets with patient and control IgG fractions on ristocetin induced agglutination. (B) Effect of washing patient platelets on ristocetin induced agglutination immediately on remixing with patient plasma and after incubation for 1 hour.

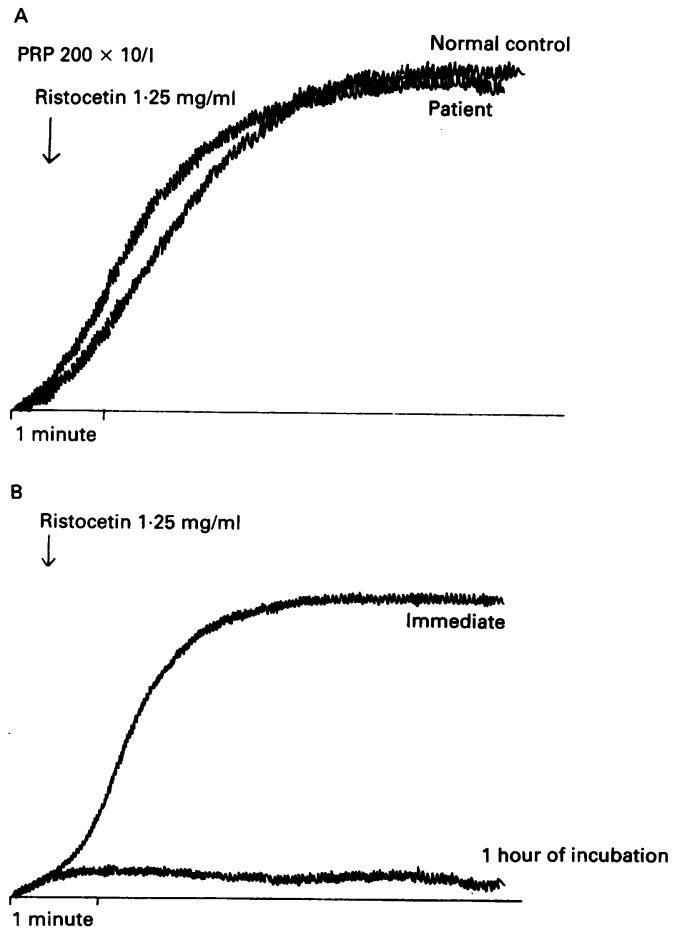

lation, resulting in an apparent deficiency of factor $\mathrm{IX}^{4}$ and other clotting factors. The in vivo importance of this inhibition was not clear. In our patients clotting screens were repeatedly normal. Both patients had prolonged bleeding times and no platelet agglutination to ristocetin. This was despite normal platelet surface glycoprotein Ib and plasma factor VIII-vWF activities. The inhibitory effect resides in the plasma, as shown by mixing studies, and is loosely associated with the platelet surface because it can be removed by simple washing, so normalising ristocetin agglutination. Myeloma proteins inhibit platelet adhesion and aggregation-particularly adenosine diphosphate induced aggregation, ${ }^{8}$ probably by coating the platelet surface. A pseudo-Bernard-Soulier syndrome has been described ${ }^{9}$ in which an autoantibody directed against GP $\mathrm{Ib}$, in a patient receiving procainamide, resulted in loss of function. In our patients, however, the IgG fraction did not inhibit ristocetin induced agglutination, despite the presence of free platelet bindable immunoglobulin in the serum. This latter is not likely to be platelet specific activity, representing HLA antibody, secondary to repeated exposure to blood products. Furthermore, simple washing is unlikely to remove specifically bound IgG, whereas in these experiments inhibitory activity was easily removed by washing.

Macromolecules in the circulation, such as hydroxyethyl starch, can induce an acquired von Willebrand type syndrome with low plasma F VIII:vWF Ag concentrations and a bleeding diathesis. ${ }^{10}$ Macromolecules, such as HES and dextran, are also adsorbed on to the platelet surface, inducing a thrombasthenic type effect. ${ }^{11}$ A similar effect probably occurs with the accumulated sphingolipid in the plasma of these patients with Gaucher's disease. An inhibitory effect on the phospholipid phases of coagulation has already been shown, and binding of glucocerebroside to the platelet surface may interfere with the vWF-ristocetin-GP Ib interaction, giving rise to the platelet function defect described here. We suggest that the term pseudo-pseudo Bernard-Soulier syndrome be applied to the abnormality in platelet function seen in these patients with Gaucher's disease. Although a plasma factor is responsible for the loss in ristocetin induced agglutination, this is not a platelet specific antibody. The effect is probably caused by excess sphingolipid directly binding to glycoprotein $\mathrm{Ib}$ or to the platelet surface adjacent to the GP on the platelet surface. Further studies are required to determine the mechanism exactly. Enzyme replacement treatment in these patients may, by reducing plasma glucocerebroside concentrations, improve the bleeding tendency.

1 Barringer JA, Ginns EI. Glucosylceramide lipidoses: Gaucher disease. In: Scriver CR, Beaudet AL, Sly WS Gaucher disease. In: Scriver CR, Beaudet AL, Sly WS, Valle $\mathrm{D}$, eds. The metabolic basis of inherited disease. New York: McGraw Hill Inc, 1989:1677-98.

2 Zimran A, Sorge J, Gross E, et al. Prediction of severity of Gaucher's disease by identifications of mutations at DNA level. Lancet 1989;ii:349-52.

3 Brady RO, Pentchev PG, Gal AE, et al. Replacement 
therapy for inherited enzyme deficiency. $N$ Engl $f$ Med 1974;291:989-93.

4 Boklan BF, Sawitsky A. Factor IX deficiency in Gaucher's disease. An in vitro phenomenon. Arch Intern Med 1976;136:489-92.

5 Benjamin D, Joshua H, Douer D, et al. Circulating anticoagulant in patients with Gaucher's disease. Acta Haematol 1979;61:223-6.

6 Machin SJ, Mackie IJ. Haemostasis. In: Chanarin I, ed. Laboratory haematology. Edinburgh: Churchill Livingstone, 1989:263-395.

7 Christopoulos CG, Kelsey HC, Machin SJ. A flow cytometric approach to quantitative estimation of platelet metric approach to quantitative estimation of platele
surface immunoglobulin. Vox Sang 1993;64:106-15.
8 Penny R, Castaldi PA, Whitsted HM. Inflammation and haemostasis in paraproteinaemias. Br $\mathcal{F}$ Haematol 1971; 20:35-44.

9 Devine DV, Currie MS, Wendell FR, et al. PseudoBernard Soulier syndrome: thrombocytopenia caused by antibody to platelet glycoprotein Ib. Blood 1987;70: 428-31.

10 Lockwood DNJ, Bullen C, Machin SJ. A severe coagulopathy following replacement with hydroxyethyl starch in a Jehovah's witness. Anaesthesia 1988;43: 391-3.

11 Mishler JM. Synthetic plasma volume expanders-their pharmacology, safety and clinical efficacy. Clin Haematol pharmacology, 